\title{
CHILD-SAN: a new disability-inclusive framework for emergency sanitation for children aged five to 11, based on a systematic review of existing guidance
}

\author{
Claire Rosato-Scott ${ }^{1 *}$ D, Barbara E. Evans ${ }^{1}$ and Dani J. Barrington ${ }^{1,2}$
}

\begin{abstract}
The specific sanitation needs of children aged five to 11 years old —-those too old to use small potties, but usually too young to safely and confidently use adult latrines during both the day and night, and including children in this age range with disabilities - have often been overlooked in the provision of emergency sanitation. There are multiple reasons to provide sanitation specifically for this age group. They represent a large number of beneficiaries; legal principles and the moral obligations of humanitarian actors should drive their inclusion. Failure to consider their needs results in increased risk of injuries, abuse and/or exploitation when using unsuitable locations to urinate or defecate, and negative health impacts arising from being unable to manage personal hygiene.

We have critically reviewed existing guidance for the provision of emergency sanitation for children aged five to 11 and subsequently presents a new disability-inclusive framework: CHILD-SAN. CHILD-SAN is an acronym representing key factors for the water, sanitation and hygiene (WASH) sector to consider in emergency sanitation programmes: child participation, heights, user-friendly, location, décor, scaled-down, accessibility, and monitoring and evaluation. The CHILD-SAN framework recommends (a) safe and meaningful child participation in emergency WASH preparedness planning and emergency WASH programming as a means to develop contextually-appropriate facilities, (b) specific design considerations for child-friendly toilets (that is, they meet the needs of a child), and (c) the collection of sex-, age- and disability-disaggregated data against contextually appropriate indicators to determine the prevalence of child-friendly facilities and their use. We found few examples of emergency WASH programmes adhering to elements of the CHILD-SAN framework, but the implementation of CHILD-SAN would contribute to the WASH sector's aims of achieving universal sanitation and maximising opportunities for good health, dignity, comfort and safety for all.
\end{abstract}

Keywords: Children, Disability, Incontinence, Latrine, Monitoring, Participation, Rights, Sanitation, Toilet

\section{Introduction}

\section{Context}

An 'emergency' is a subjective concept which can be defined as 'a situation that threatens the lives and

\footnotetext{
*Correspondence: cncr@leeds.ac.uk

${ }^{1}$ School of Civil Engineering, University of Leeds, Leeds, West Yorkshire LS2 9JT, UK

Full list of author information is available at the end of the article
}

well-being of large numbers of a population and requires extraordinary action to ensure their survival, care and protection' (UNICEF 2010, p.4). In an emergency, community and state institutional structures and services are ruptured, and families and communities are brokenup or displaced (Tanner and O'Connor 2017). In such contexts, children are particularly vulnerable. The Core Commitments for Children in Humanitarian Action outline programme commitments for the initial response 
to an emergency, with the water, sanitation and hygiene (WASH) sector aiming to prevent and reduce mortality and morbidity by minimising the spread of disease (UNICEF 2010). In addition, WASH actors are expected to ensure that all people have access to adequate and equitable sanitation and hygiene, and the maximisation of opportunities for good health (defined by the World Health Organisation (WHO) as complete physical, mental and social well-being), dignity, comfort and safety (WHO 2006; United Nations 2016; Sphere Association 2018; Groupe URD 2019). Whilst these aspects should be considered from the beginning, increasing attention and time will be spent on ensuring their achievement over time.

There has been a reasonable amount of research into how emergency WASH interventions provide sanitation for both children under- 5 years old (due to the significant health risks their faeces represent) and adults (aged 18 years and over) during both the initial and longer-term response. Yet the specific sanitation needs of those too old to use small potties but usually too young to safely and confidently use adult toilets during both the day and night (defined for our purposes as aged from 5 to 11 years old), and including children with disabilities, are often overlooked (Visser 2012).

\section{Children and emergencies}

Cultural definitions of the upper limit of childhood may vary, but the United Nations (UN) Convention on the Rights of the Child (CRC) defines a child as 'every human being below the age of 18 years unless under the law applicable to the child, majority is attained earlier' (Part I, Article 1) (UN 1990). While the specifics of definitions may vary, the general point remains; children are particularly vulnerable in an emergency and children under 15 'suffer the most' (Global WASH Cluster 2019, p.7).

The United Nations Office for the Coordination of Humanitarian Affairs (OCHA) estimates that in 2021, 235 million people will need humanitarian assistance and protection. This means 1 in 33 people worldwide needs help (OCHA 2020, p.9). At the end of 2019, the United Nations High Commissioner on Refugees (UNHCR) estimated that there were 87.63 million persons of concern, being any person whom the UNHCR considers to be a refugee, a returnee, stateless, internally displaced or an asylum-seeker (UNHCR 2020). Of these, the UNHCR had demographic data on 36 million: over half (19 million) were under 18 years of age, and 1 in 5 (7.86 million) were aged between 5 and 11 years of age (UNHCR 2020).

During the disruption of an emergency children of any age and ability face a range of heightened risks-particularly if separated from family and/or caregivers-including disease, a disrupted education, gender-based violence including sexual violence and exploitation, malnutrition, neglect, physical and emotional abuse, psychosocial distress, trafficking and recruitment into armed groups (Tanner and O'Connor 2017; Sphere Association 2018; UNICEF 2018). Further, whilst usually dependent on others to provide their needs, including safe food and water, shelter and healthcare, in an emergency children may necessarily be dependent on adults who are not be part of their usual network of caregivers.

The Core Commitments for Children in Humanitarian Action (CCCs) are a global framework for humanitarian action for all children guided by international human rights law (including the Convention on the Rights of the Child and international humanitarian law), and based on global standards and norms for humanitarian action (UNICEF 2010). The CCCs outline the programme commitments for action in the first 8 weeks of an emergency response and provide guidance for action beyond that period by six sectors: nutrition, health, HIV and AIDS, education, child protection, and WASH (UNICEF 2010).

\section{The WASH sector in an emergency}

Oxfam (2013, p.4) considers that 'WASH' incorporates water (clean water supply for human consumption, hygiene and household needs), sanitation (excreta disposal, solid waste management, drainage and vector control) and hygiene (community mobilisation and engagement, information, education and communication, non-food item distributions and health data monitoring). In the first stages of an emergency response, the core mandate of WASH interventions is to prevent and reduce mortality and morbidity by minimising the spread of disease, primarily through the separation of humans from faecal matter. They are 'not necessarily intended to provide long-term sustainable access, but instead provide rapid relief' (Yates et al. 2018, p.32).

The WHO recognises four stages of response to an emergency, with timings being context-specific: first steps (normally the first week), emergency response (normally the first month), continuing response/consolidation (beyond the first month) and phasing out/recovery (WHO 2008). WASH interventions must adapt as the emergency progresses to beyond providing 'rapid relief' in the initial (first steps and emergency response) phases. In the continuing response/consolidation phase, efforts aim to shift from the provision of communal solutions to culturally appropriate and sustainable householdlevel solutions informed by the equitable participation of the affected population (Gensch et al. 2018). During the phasing out/recovery phase, infrastructure development continues and the participation of stakeholders continues to increase, to facilitate handover to households or local and longer-term partners (Gensch et al. 2018). 
Humanitarian Response Plans (HRPs) are prepared for a protracted or sudden onset emergency that requires international humanitarian assistance (OCHA 2019). Initially prepared for a year, they are annually updated as the emergency progresses: the average length of an HRP, and therefore the associated emergency response, is 9.3 years (OCHA 2018). During that time, there will be multiple WASH interventions, with differing objectives. The Sphere Handbook (Sphere Association 2018) is generally considered by the humanitarian sector to represent best practice guidance for the delivery of emergency sanitation interventions. Sphere states that a key activity of emergency WASH interventions is 'ensuring conditions that allow people to live with good health, dignity, comfort and safety' (Sphere Association 2018, p.92), with the WHO defining health as 'a state of complete physical, mental and social well-being and not merely the absence of disease or infirmity' (WHO 2006). Further, the Sustainable Development Goals (SDGs) aim to 'achieve access to adequate and equitable sanitation and hygiene for all ... paying special attention to the needs of women and girls and those in vulnerable situations' by 2030 (SDG Target 6.2) (United Nations 2016). Prior to the SDGs, the main priority had been the provision of basic sanitation at the household level with other settings receiving less attention: to achieve universal access other settings now need to be considered, including those of involuntarily displaced populations (Behnke et al. 2018).

It is within this context that we seek to (a) critically review existing guidance for the provision of emergency sanitation for children specifically aged five to 11 (being those too old to use small potties, but usually too young to safely and confidently use adult toilets during both the day and night, including children with disabilities), (b) present a new disability-inclusive framework (CHILDSAN) that the WASH sector can use to better provide emergency sanitation for this somewhat forgotten age group and (c) critically assess existing facilities against the CHILD-SAN framework.

\section{Methods}

\section{Systematic review}

A systematic method was used to search for publications which (a) discussed or reported on emergency sanitation for children; (b) were published in 2004 or later, being the year that the Sphere Handbook (Sphere Association 2018) first included children as a cross-cutting theme; and (c) were written in English or Spanish (being the languages spoken by the lead author) (Criterion 1). Full texts of publications that met Criterion 1 were assessed to determine whether they provided guidance on (Criterion 2a) and/or reported on the provision of emergency sanitation for children (Criterion 2b), including those aged five to 11 . The publications which met Criterion 2a and/ or b were qualitatively analysed (Fig. 1).

A search of the peer-reviewed literature was conducted on March 3, 2019. The Scopus and Web of Science databases were searched for articles published since 2004 using the search string '(emergency OR disaster OR humanitarian OR crisis) AND (sanitation OR toilet OR latrine OR 'solid waste management') AND (child*)' which returned 247 and 233 results, respectively. The titles and abstracts (where necessary) of these records were screened according to Criterion 1, resulting in 21 articles from which eight duplicates were removed. Each article was then assessed to determine whether it met Criterion 2a and/or 2b, of which six did.

To identify grey literature records for inclusion the following were screened: (a) bibliographies of the six peer-reviewed articles which met Criterion $2 \mathrm{a}$ and/or $2 \mathrm{~b}$; (b) the websites of the 41 organisations that are full members of the Global WASH Cluster ${ }^{1}$; and (c) Google using the search term 'emergency sanitation children' (with the first 120 results assessed, after which saturation was reached as results were not relevant). Requests for information were also sent to known experts in the Emergency WASH sector, including to an informal email group of individuals with an interest in incontinence in low- and middle-income countries $(44$ members at time of the request, December 17, 2018), and to the Emergency WASH Google Group which is maintained by the Global WASH Cluster and USAID (227 members at time of the request, March 13, 2019). The full text of each publication that met Criterion 1 was assessed to determine whether it met Criterion 2a and/or 2b.

The bibliographies of all grey literature publications that met Criterion 2a and/or b were screened for publications that met Criterion 1, with the full text of those that did assessed to determine if they met Criterion $2 \mathrm{a}$ and/ or $\mathrm{b}$. This process was repeated until no new publications were identified.

\footnotetext{
1 The 41 organisations that are full members of the Global WASH Cluster are Action contra la Faim, Adventist Development and Relief Agency, Care International, Catholic Agency for Overseas Development, Catholic Relief Services, Clean the World Foundation, Concern Worldwide, German WASH Network, GOAL, International Federation of Red Cross and Red Crescent Societies, International Medical Corps, IMPACT Initiatives, International Organisation for Migration, International Rescue Committee, Islamic Relief, Medair, Mentor Initiative, Mercy Corps, Norwegian Church Aid, Norwegian Refugee Council, Oxfam International, Plan International, Polish Humanitarian Action, Population Services International, Red Cross Austria, Relief International, Samaritan's Purse, Save the Children UK, Solidarites International, Tearfund, Terre des Hommes, THW (Germany), World Vision, UN Development Programme, UN Environment Programme, UN Habitat, UN Refugee Agency, UN International Children's Emergency Fund, UN Relief and Works Agency, World Food Programme and World Health Organisation.
} 

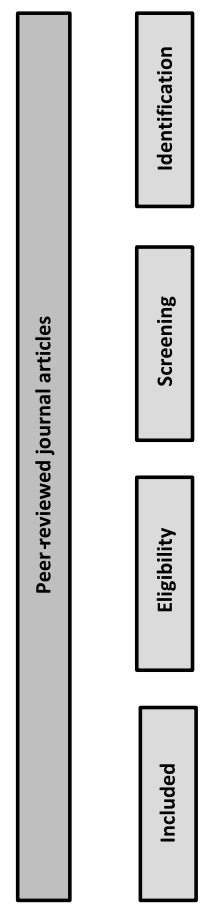

Peer reviewed articles

identified through search of

Scopus and Web of Science

$$
(n=480)
$$
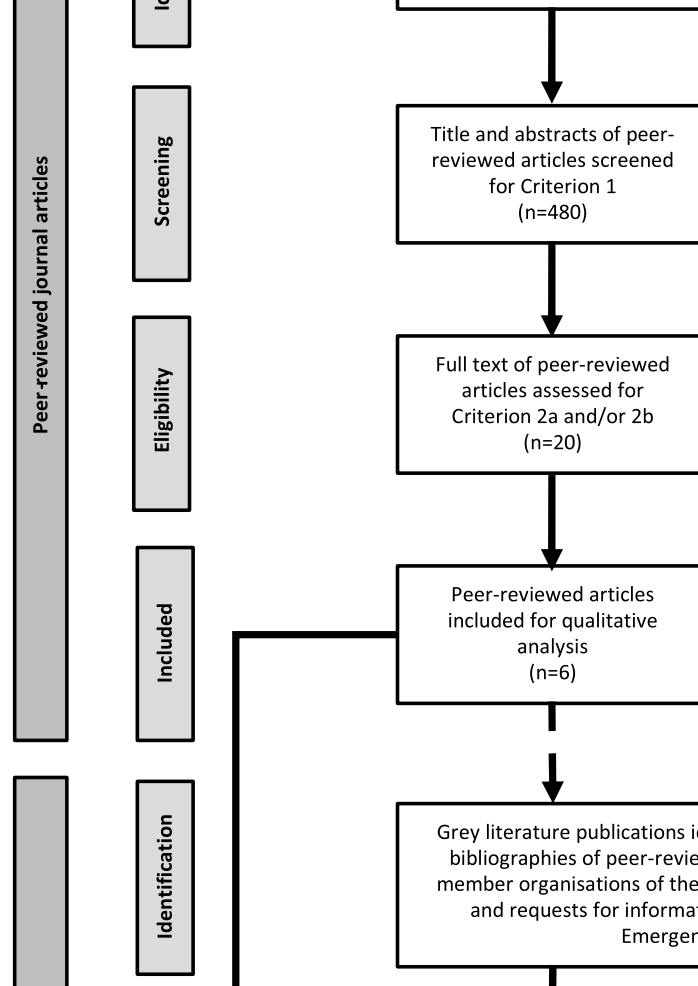

Title and abstracts of peerreviewed articles screened for Criterion 1 $(n=480)$

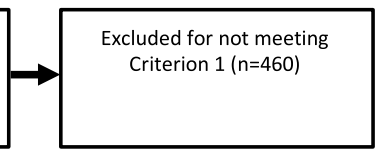

Full text of peer-reviewed

articles assessed for

Criterion $2 a$ and/or $2 b$

$$
(n=20)
$$

Excluded for not meeting

Criterion $2 \mathrm{a}$ and/or $2 \mathrm{~b}$ $(n=6)$

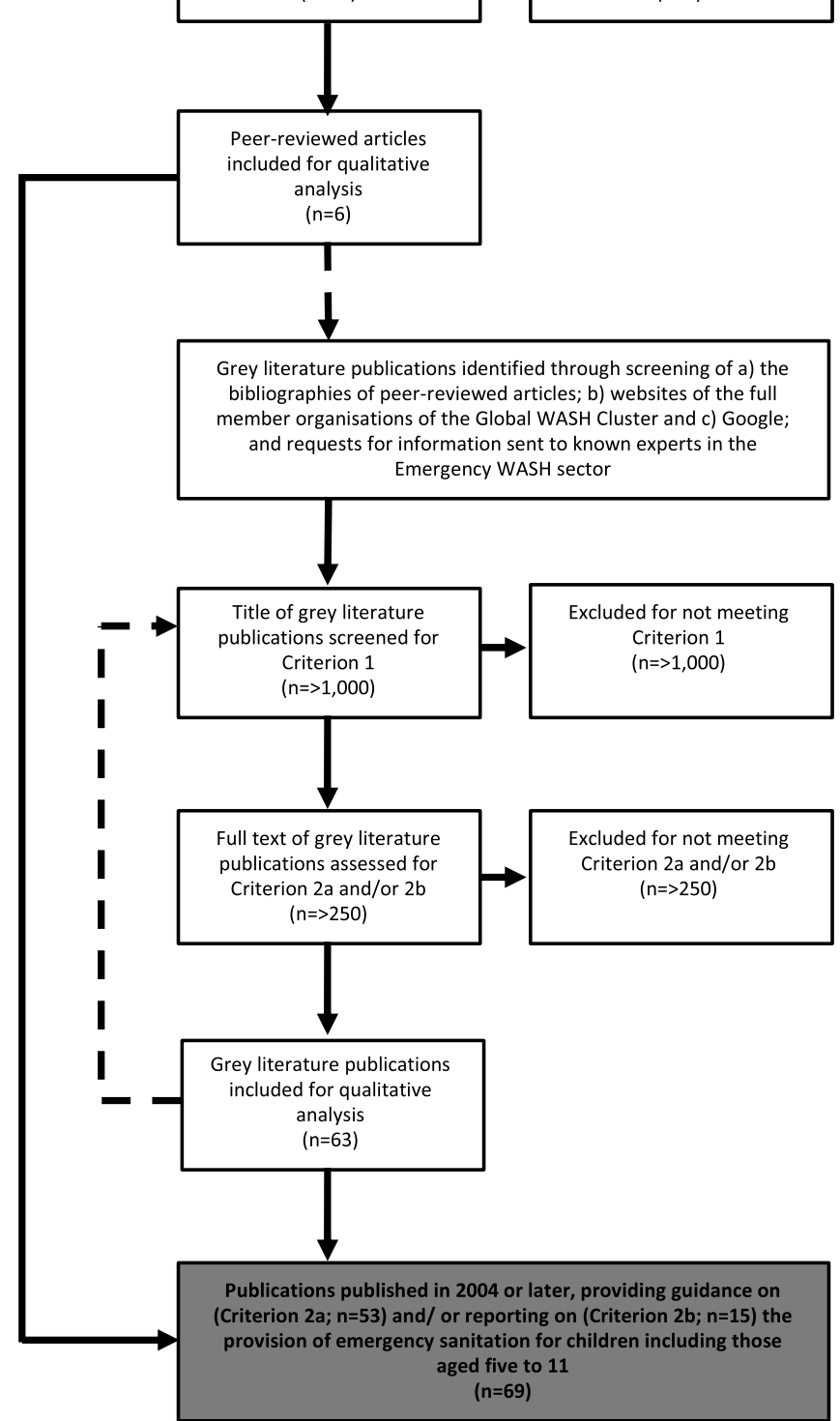

Fig. 1 Systematic review: methodology 
Process of identifying peer-reviewed and grey literature publications for review. Criterion 1 being publications which (a) discussed or reported on emergency sanitation for children, (b) were published in 2004 or later, and (c) were written in English or Spanish. The 69 publications that met Criterion 2 were classified as either providing guidance on (Criterion 2a) or reporting on (Criterion 2b) the provision of emergency sanitation for children aged five to 11 (see Supplementary Information Table 1). The dashed lines indicate where bibliographies were used to identify further publications. The figure was developed from the PRISMA Statement (Moher et al. 2009).

\section{Analysis}

Publications that provided guidance on the provision of emergency sanitation for children including those aged five to 11 (Criterion 2a) were inductively coded using NVivo 12. The codes (Table 1) assigned a summative attribute to a portion of data and this system was used to identify emerging themes and to highlight pertinent excerpts which were specifically relevant to children aged five to 11. The identified themes were amalgamated to develop a new disability-inclusive framework for the provision of emergency sanitation for children aged five to 11: CHILD-SAN.

The publications that reported on the provision of emergency sanitation for children including those aged five to 11 were also inductively coded using NVivo 12 . The codes (Table 2) assigned a summative attribute to a portion of data and this system was used to identify examples of emergency sanitation for children aged five to 11 , or the monitoring and evaluation of emergency sanitation for children aged five to 11 . Once identified, these examples were critically assessed against the newly developed CHILD-SAN framework. Note that some publications provided guidance on, and reported on, the provision of emergency sanitation for children including those aged five to 11 . These publications were therefore coded twice.

\section{Findings}

\section{The definition of 'sanitation'}

The WHO defines sanitation as 'the provision of facilities and services for the safe management of human excreta ... (and) also includes the safe management of solid waste and animal waste' (WHO 2018). Some authors of reviewed publications, including this one, prefer to broaden this definition from the protection of personal, public and environmental spaces: Langford et al. (2017, pp.348-349) for example, add that sanitation is also 'the ability to effectively access space and facilities (whenever and wherever needed) that afford privacy, dignity and safety in which to urinate, defecate and practice related hygiene, including menstrual health management, in a culturally acceptable manner.'

There is an extensive and diverse literature providing guidance for the delivery of emergency sanitation interventions. Emergency sanitation for children is referenced in varying degrees throughout the literature, but needs at different ages are rarely considered. Most guidance focuses on participation in behavioural change programme design (especially for hygiene management programmes, usually hand-washing before touching food and after contact with excreta) and excreta management (largely for children under the age of five) and hygiene promotion. Specific considerations for children aged five to 11 were found only with regard to the provision of toilets and handwashing facilities. Note that we have used the term 'toilet' to mean any 'facility or device that immediately contains excreta and creates the first barrier between people and the waste' (Sphere Association 2018, p.113).

\section{A critical review of existing guidance}

Guidance for the provision of emergency sanitation for children aged five to 11 generally fell into three categories: ensuring safe access, adaptations to facilitate use, and improving a child's experience of using a toilet.

Table 1 Codebook for Criterion 2a publications

\begin{tabular}{ll}
\hline Code & Definition of the text to which the code relates \\
\hline Definitions & Definitions of key terms \\
Emergency statistics & Key data points related to emergencies \\
Guidance, general & General guidance for emergency WASH interventions \\
Guidance, M\&E & General guidance for the monitoring and evaluation of emergency interventions \\
Response phases & Descriptions of emergency response phases \\
Response principles & General principles guiding the WASH-sector's response to emergencies \\
Solid waste management & Any reference to children and solid waste management \\
Toilets & Any reference to children and toilets (including latrines) \\
\hline
\end{tabular}


Table 2 Codebook for Criterion 2b publications

\begin{tabular}{ll}
\hline Code & Definition of the text to which the code relates \\
\hline Examples, M\&E & Real-life examples of the M\&E of emergency interventions \\
Examples, sanitation & Real-life examples of emergency sanitation for children \\
Use of toilets statistics & Data points related to the use of toilets by children \\
\hline
\end{tabular}

\section{Ensuring safe access}

For a child to be able to use a toilet they must be able to safely access it, and the guidance notes that paths should be wide enough for two people (for example, a caregiver and child) to comfortably pass (Ferron and Lloyd 2014). We note that caregivers may not always be available or willing to accompany a child to the toilet however, for example, in cultures where the practice of Purdah is followed such as the Rohingya community in Cox's Bazar, Bangladesh (House 2019). Therefore, the ability of a lone child to navigate the approach (both in terms of distance and topography) must also be considered.

\section{Adaptations to facilitate use}

The guidance acknowledges that toilets need to be adapted for the use by children with disabilities, and because children are smaller and have less physical strength relative to adults (UNICEF 2012). Features to be adapted include the heights of door handles, locks and handrails (Save the Children 2013); toilet seat and squatting plate dimensions (Banzet 2003; Ferron and Lloyd 2014); the size of drop-holes (Noortgate and Maes 2010); and the ease of use of doors, taps for handwashing and water for anal cleansing (Zomerplaag and Moojiman 2005).

Within the existing guidance for emergency sanitation for children aged five to 11, UNICEF (2017b) provides indicative sizings for adaptations to be made to toilets for children with disabilities; Noortgate and Maes (2010) provide indicative child-friendly (that is, they meet the needs of a child) latrine slab sizings (a latrine slab is a cover for the latrine pit with a hole to the pit below; users stand on the slab when using the latrine). In Zomerplaag and Moojiman's (2005) guidance for child-friendly hygiene and sanitation facilities in schools, they state that it is not possible to set international standards for facility dimensions because the heights and sizes of children will vary. Instead, they advocate conducting a participatory exercise to determine contextually appropriate dimensions. Whilst this is an ideal approach and should always be conducted, such an exercise may not be possible in the initial (first steps and emergency response) phases of an emergency and the user population may also be frequently changing. As the absence of technical guidance may deter adaptations or result in unsuitable adaptations, we have used the indicative sizings as recommended by UNICEF (2017b), but we encourage the participation of children to improve the designs and to ensure that they are contextually appropriate.

\section{Improving a child's experience of using an emergency toilet}

Spaces such as toilets provide child (and adult) users with a range of positive and negative experiences related to colours, smells, shapes and sounds (UNICEF 2012). The guidance suggests a number of ways to improve a child's experience of using emergency toilets, including a higher ratio of facilities to children than for adults to lower waiting-times (Noortgate and Maes 2010; Ferron and Lloyd 2014), enough space for both the child and carer (UNHCR 2018a), open and light structures (Zomerplaag and Moojiman 2005; Deniel 2006) and bright décor (Zomerplaag and Moojiman 2005).

The guidance often assumes that the primary caregiver is the mother, and some guidance recommends positioning gender-neutral children's toilets near to adult female toilets (SuSanA 2012). However, primary caregivers will not always be female, and it may be contextually appropriate to also position gender-neutral children's toilets near to adult male toilets. Yet an 8-year-old girl with a male caregiver may feel uncomfortable using a toilet located close to the adult male toilets and may also feel uncomfortable using a gender-neutral children's toilet located close to the adult female toilets alone and potentially with boys. This emphasises the need for community participation in the design and location of facilities as soon as possible to determine what is culturally and contextually appropriate.

\section{CHILD-SAN: a new disability-inclusive framework for emergency sanitation for children aged five to 11}

Using and building upon the existing guidance, we present a new framework for the provision of emergency sanitation for children aged five to 11: CHILD-SAN. CHILD-SAN is an acronym that the WASH sector can use to better provide sanitation facilities for children to use, and includes a number of specific considerations when designing toilets for this age group (Table 3). It is a disability-inclusive framework, that is, it promotes the 
Table 3 CHILD-SAN: a new disability-inclusive framework for emergency sanitation for children aged five to 11

C Child participation

H Heights

I user-friendly
- Ensure (a) safe, meaningful and disability-inclusive child participation in emergency WASH preparedness planning and (b) meaningful and disability-inclusive participation in emergency WASH programming from the earliest opportunity that it is safe to do so using existing guidelines (notably O'Kane 2013a)

- See The case for CHILD-SAN facilities section for discussion

- Door handles (if being used) should be mounted 800 to 900 mm above the floor (UNICEF 2017a)

- Locks (if being used) should be positioned within reach of a child or wheelchair user, at a height of between $680 \mathrm{~mm}$ and $800 \mathrm{~mm}$ (Save the Children 2013; UNICEF 2017a)

- Grab rails on each side of the toilet should be located 300 to $350 \mathrm{~mm}$ from the centre of the toilet and between

$510 \mathrm{~mm}$ and $640 \mathrm{~mm}$ off the ground (UNICEF 2017a)

- Water taps should be positioned within reach of a child or wheelchair user, at a height of between 680 to $800 \mathrm{~mm}$ (UNICEF 2017a)

- Washbasins (with unobstructed knee clearance for wheelchair users) should be positioned at height of between 650-700 $\mathrm{mm}$ and $200 \mathrm{~mm}$ deep (UNICEF 2017a)

- Consider if (verbal or visual, using simple communication methods) guidance on how to use the toilet needs to be provided

- Children are often not prepared to wait, or do not have sufficient bowel or bladder control to wait, and pits may also fill-up relatively more quickly as children drop items down the hole both on purpose and accidentally (Ferron and Lloyd 2014). A ratio of 1 toilet per 20 children is recommended (Noortgate and Maes 2010)

- Allow for a spare $0.5 \mathrm{~m}$ of depth in the latrine pit size to avoid unpleasant sights and excreta splashing out during use. A pit with a maximum depth of $2 \mathrm{~m}$ (an effective depth of $1.5 \mathrm{~m}$ ) will therefore last for about 2 years if it is used normally by 20 children (an accumulation rate of $0.04 \mathrm{~m}^{3} /$ child) (Noortgate and Maes 2010)

- Consider how open the toilet should be. Children, particularly younger children, may prefer an open structure without a door, roof (this may be climate-dependent) or superstructure (Deniel 2006). Such structures alleviate fears of the dark, and younger children also like to imitate and observe others (Zomerplaag and Moojiman 2005)

- Provide enough space for two people (for example, a caregiver and child) to use the toilet to enable supervision, help and teaching (UNHCR 2018a), and that accommodates a wheelchair turning radius ( $1500 \mathrm{~mm}$ by $1500 \mathrm{~mm}$ ) (UNICEF 2017a)

- Ensure that doors (if being used) are robust but not too heavy for children to use (Zomerplaag and Moojiman 2005). D-lever door handles are preferred rather than doorknobs (Jones and Wilbur 2014; UNICEF 2017a)

- If a toilet seat or chair is being used, grab rails should be provided on each side of the toilet. One should be moveable or foldable on one side to allow for transferring (UNICEF 2017a)

- Provide a handle bar and/or handrails to support squatting. Multiple handrails may be needed (vertical, horizontal, various heights) (Noortgate and Maes 2010; Ferron and Lloyd 2014; Jones and Wilbur 2014)

- Provide doors with locks and walls that ensure privacy; easy access to water; hooks and shelves; and discrete disposal facilities to aid the changing of soiled menstruation and incontinence products and clothing. Note that the whole collection and disposal chain of soiled items also needs to be considered (Sommer et al. 2017)

- Ensure that taps are robust but not too heavy for children to use (Zomerplaag and Moojiman 2005). Large taps with long levers are easier to operate (UNICEF 2017a)

- Locate soap for ease of use and where a child with visual or mobility disabilities can easily find/reach it (UNICEF 2017a)

L Location - Consider (distance/location) where to safely position gender-neutral and gender-segregated children's toilets that is culturally appropriate for both the child and caregiver

- Brightly decorated walls can encourage use, and decoration with child-friendly hygiene promotion material can increase awareness at the same time (Zomerplaag and Moojiman 2005)

- Decoration can include'nudges' to use handwashing facilities, for example, footsteps from the toilet to the handwashing facilities

- Involving children in decoration can encourage a sense of ownership and deter vandalism (SuSanA 2012)

- Drop-holes should not be so big that a child could fall-in, or be fearful of falling-in: Noortgate and Maes (2010, p.31) provide an indicative diameter of $120 \mathrm{~mm}$

- Toilet-seats should be low (350 to $450 \mathrm{~mm}$ from floor level) (UNICEF 2017a) or a step provided for children to access the toilet-seat (Banzet 2003) although this may limit access for children with disabilities

- Squatting plate dimensions (including the distance between footrests of a squatting platform and the distance from a squatting platform to the wall) should be suitable for a child; indicative dimensions have been provided by Noortgate and Maes (2010, p.31). Smaller squatting plates can be fixed over adult ones (UNICEF 2017b) 
Table 3 (continued)

A Accessibility
- Consider accessibility for both the child and caregiver
- Position well-lit signs to show the location of the toilets at both adult and child-height, and use simple communica-
tion methods, for example, symbols (UNICEF 2017a)
- Paths should be wide enough for two people (for example, a caregiver and child) to comfortably pass (Ferron and
Lloyd 2014), and ideally $1800 \mathrm{~mm}$ wide to allow two wheelchair users to pass (UNICEF 2017a)
- Distances and topography of paths must be appropriate for all children and caregivers to navigate
- Line paths with painted rocks and provide painted landmark posts to increase visibility (Jones and Wilbur 2014)
- Ramps are the preferred solution for access to at least some of the facilities and where used they should have a
minimum width of $1000 \mathrm{~mm}$ with raised, painted sides (to avoid falling and to increase visibility) and painted handrails
recommended for slopes steeper than 1:20 (Jones and Wilbur 2014; UNICEF 2017a)
- If there are steps, the step riser height (150 to 170 mm) and step depth (280 to 420 mm) should be suitable for a child,
the step surface should be textured to prevent slippage, and a painted handrail provided for visible support (Ferron
and Lloyd 2014; Jones and Wilbur 2014$)$
- Entrances should have a minimum width of 800 mm to allow wheelchair access with no thresholds or barriers on the
ground (UNICEF 2017a)
- Doors (if being used) should open outwards (Jones and Wilbur 2014)
- Ensure the collection of sex-, age- and disability-disaggregated data against contextually appropriate indicators-
including the WASH and Child Protection indicators of the Minimum Standards for Child Protection in Humanitarian-
to indicate the prevalence of child-friendly facilities and their use
- Consider if cleaning and maintenance exploits children and/or discriminates against girls (Save the Children 2013)
SeeCHILD-SAN: a new disability-inclusive framework for emergency sanitation for children aged five to 11 section for discus-
sion

construction of toilets that are accessible to all children within this age group, following the principles of universal design (UNICEF 2017a).

\section{An assessment of existing toilets against the CHILD-SAN framework}

For a child to use an emergency toilet, they must (a) want to use it and (b) be able to use it. The premise of the CHILD-SAN framework is that it will result in toilets that children aged five to 11 will want, and are able, to use. The assumption is that the collection of usage data will indicate the prevalence of such facilities: usage will be higher if facilities adhere to the recommendations of the CHILD-SAN framework.

The UNHCR monitors and evaluates WASH conditions for all recognised refugee and internally displaced people (IDP) settlements, with initial 'emergency standards' (general guidance is that these are for use up to and including the first 6 months after population movement has stabilised, but definition is context-specific), and longer-term 'post-emergency standards' subsequently (UNHCR 2018b). Additional monitoring frameworks may also be used according to context, for example, to incorporate national standards and/or to include specific field indicators. The UNHCR Core WASH Indicators and associated minimum standards related to toilets are as follows:

- Number of persons per toilet, noting that toilets should be facilities that are cleanable, guarantee privacy and are structurally safe (Emergency standard 1:50/post-emergency standard 1:20 aiming for one latrine per household as soon as possible)

- Percentage of households with household toilet (post-emergency standard 85\%)

- Percentage of households reporting defecating in a toilet (emergency standard 60\%/post-emergency standard 85\%)

- In schools, 50 pupils per toilet on average, being 30 girls per toilet and 60 boys per toilet with additional urinals provided for boys

- In healthcare facilities, 20 outpatients per toilet, and 10 inpatients/beds per toilet (UNHCR 2018b).

Sphere recommends disaggregating data 'to the extent possible and with categories appropriate to the context to understand differences based on sex or gender, age, disability, geography, ethnicity, religion, caste or any other factors that may limit access to impartial assistance ... for general data on age use the same cohorts as in national data-collection systems' (Sphere Association 2018, p.12). In the absence of national age cohorts, Sphere recommends the age brackets 0 to 5 years, 6 to 12 years, and 13 to 17 years for children (Sphere Association 2018, p.13). Yet Mazurana et al.s (2013) review of the collection of sex-and age-disaggregated data (SADD) in humanitarian responses found that the collection of SADD was 'extremely limited, ad hoc and sporadic' (p.S77). Further, even when SADD is collected, the majority of those interviewed believed that 'field officers do not necessarily know what to do with it' (Mazurana et al. 2013, p.S78). House (2019) also found that in Cox's Bazar, Bangladesh, although the Gender in Humanitarian Action (GiHA) 
cross-sectoral group had been encouraging the collection of SADD, it had overlooked data on disability.

Mazurana et al's and House's findings were reflected in the lack of data we found on the provision and use of toilets by children aged five to 11 . Although anecdotal evidence of CHILD-SAN facilities (or the lack thereof) was noted, no quantitative data was found. Positive reports, with the CHILD-SAN attributes acknowledged noted inboldwhere sufficient detail is provided, included the following:

- In Rwanda in 1994, open child latrines with smaller squat holes were provided in IDP camps to be used by children aged two and older. Similar latrines was used in IDP camps in Uganda in 2006 (Harvey 2007) (CHILD-SAN)

- Dropholes with dedicated cubicles for children were installed in the Petion Ville Golf Course camp in Port-au-Prince, Haiti (Bastable and Lamb 2012) (CHILD-SAN unknown)

- Yates et al. (2018) conducted a systematic review on the efficacy and effectiveness of short-term WASH interventions in emergency responses in low- and middle-income countries. The review found that when designing latrines, specific consideration for women and vulnerable populations including children were documented in South Sudan, India, and Liberia. This led to more appropriate latrine designs with marginal additional costs (CHILD-SAN unknown)

- In the informal tented settlements of the Bekaa Valley, Lebanon, locks at child-height were added to the latrines (Jabbar 2018) (CHILD-SAN)

- The UN Children's Fund (UNICEF) is trialling an accessible latrine slab for emergencies in Angola with users to include children (UNICEF 2017b) (CHILDSAN).

Negative anecdotes, with the CHILD-SAN attributes not acknowledged noted inboldwhere sufficient detail is provided, included:

- In the Bahn refugee camp in Nimba, Liberia, 700 children aged five to ten were identified, but the WASH programme evaluator had no information that their specific sanitation needs were addressed outside of the schools (Visser 2012) (CHILD-SAN unknown)

- In Ferron and Lloyd's (2014) study of emergency sanitation for children, $29 \%$ of respondents had provided child-friendly toilets in schools, but only $16 \%$ had provided child-friendly toilets in commu- nity settings. Whereas child-friendly WASH facilities were sometimes provided in health centres and most often provided in child-friendly spaces (CFSs, safe places for children). Further, informants noted that the needs of different age groups of children were not considered (CHILD-SAN unknown)

- In the province of Leyte in the Philippines posttyphoon Haiyan, children aged between 2 and 7 years old reported finding ceramic bowl toilets difficult to use and were sometimes afraid of using the 'Comfort Rooms' due to the lack of handrails, an unfamiliarity with using a ceramic bowl toilet, not liking the feel of the ceramic bowl toilet and/or a fear of sitting on it, and a fear that the toilet hole was too big (Denis 2015) (CHILD-SAN)

- In Cox's Bazaar, Bangladesh, women reported giving their children less food to avoid using the latrine at night (Farrington 2018) (CHILD-SAN)

- Also in Cox's Bazar, House (2019) noted that, in one CFS visited that although the toilet units themselves were well designed for children, the entrances to the male and female toilet doors were situated together behind the same wall without a division, so that males had to walk by the female door to access the male urinals (CHILD-SAN)

- Bedwetting by children has been noted by NGO workers in refugee camps (Veneme 2015; Farrington 2019; House 2019). Whilst some children may be experiencing urinary incontinence (the involuntary leakage of urine during the day and/or at night), some instances may be due to a reluctance to use the existing facilities (social incontinence) (CHILD-SAN unknown).

The lack of quantitative data can be attributed to a multitude of reasons, not least the challenges of collecting data in emergency contexts and the prioritisation of response activities (Yates et al. 2018). But as Mazurana et al. (2013, p.S79) concluded, 'the additional time and resources needed to (collect SADD) are justified by the improvements in programming and by avoiding costly programme failures due to errors in targeting and design.

We reiterate Mazurana et al.s (2013) recommendation that SADD is collected in all phases of an emergency to inform the response and further expand this to include data disaggregated by disability (assessed using the Washington Group/UNICEF child functioning question set) as recommended by the Age and Disability Consortium (ADCAP) (Age and Disability Consortium 2018) (Table 3). Collecting data to determine the percentage of households reporting defecation in a toilet disaggregated by sex, age and disability would indicate the prevalence of child-friendly facilities and their use, the assumption 
being that usage would be higher if facilities addressed the CHILD-SAN recommendations. It is also recommended that the WASH and Child Protection indicators and targets of the Minimum Standards for Child Protection in Humanitarian Action are adapted to the context and used in conjunction with the Sphere standards as soon as possible (Table 3). Those related to toilets are as follows:

- Percentage of WASH projects where child safety and wellbeing are reflected in the initial risk assessment, design, monitoring and evaluation framework (Target $100 \%)$

- Percentage of surveyed sites with separated communal facilities (toilet and bathing facilities) for girls/ women and boys/men (Target 100\%)

- Percentage of surveyed sites with communal facilities that meet $90 \%$ of safety criteria (Target $100 \%$, safety criteria defined using in-country checklist)

- Percentage of schools, play areas, health centres etc., that include child-appropriate WASH facilities (Target $100 \%$, child-appropriate defined in-country)

- Percentage of accessible WASH facilities (for children with disabilities, adolescent girls) (Target 100\%) (The Alliance for Child Protection in Humanitarian Action 2019)

The recommendation to consistently use known standards in monitoring frameworks aligns with the initial findings of the Quality Assurance and Accountability Project (QAAP), which is an ongoing Global WASH cluster initiative to determine how best to measure quality in humanitarian WASH responses (Brown 2019).

\section{The case for CHILD-SAN facilities}

If there are many reasons why child-friendly toilets for children aged five to 11 are not always provided, and why data disaggregated by sex, age and disability is not always collected and/or actioned to determine if they are being provided and used, there are just as many reasons advocating for CHILD-SAN facilities. The first is the sheer number of beneficiaries: in 2019, 1 in 5 known persons of concern were aged between 5 and 11 years of age (UNHCR 2020).

If there are facilities available but a child does not want to or cannot use them, they may choose to urinate and defecate elsewhere instead, for example, outside or within a shelter. House (2019) found that some children in the Cox's Bazar refugee camps (Bangladesh) were fearful of using the toilets, but urinating or defecating elsewhere may also expose the child to risks of injuries, abuse and/or exploitation (UNICEF 2017a). Habitually delaying urination until a suitable place is found also increases the risk of developing urinary incontinence (the involuntary leakage of urine) due to bladder dysfunction (Zhou et al. 2019). A child may also urinate or defecate on themselves instead of using what is felt to be an unsuitable toilet, which is known as 'social incontinence' (Ryan 2018). Children that wet themselves can suffer from incontinence associated dermatitis (IAD; similar to nappy rash), skin infections, pressure sores, urinary tract infections and dehydration (if fluid restriction is used as a management strategy) (RosatoScott et al. 2019). The social and emotional impact on their lives and their carers' lives can also be significant: any resultant personal embarrassment and shame, or social ostracism (for example, due to smell) can prevent participation in programming, education and social activities (Hafskjold et al. 2016).

There are also legal arguments. The Convention on the Rights of the Child states that 'children have the right to ... a clean and safe environment' (Article 24) (UN 1990). Decades later, the Human Rights to Water and Sanitation (HRWS) were recognised by the UN General Assembly on July 28, 2010 (Resolution 64/292), and recognised in international law by the Human Rights Council's Resolution 15/9 on September 30, 2010 (United Nations 2010a, b). Sanitation was later recognised as a distinct and separate human right by the UN General Assembly on December 17, 2015 (Resolution 70/169), which stated that the human right to sanitation entitles everyone, without discrimination, to have physical and affordable access to sanitation, in all spheres of life, that is safe, hygienic, secure, socially and culturally acceptable and that provides privacy and ensures dignity' (United Nations 2015).

To achieve this human right, the international community are striving to attain SDG Target 6.2, which aims to 'achieve access to adequate and equitable sanitation and hygiene for all ... paying special attention to the needs of women and girls and those in vulnerable situations' by 2030 (United Nations 2016). Given the broad definition of sanitation that we have used, the provision of CHILD-SAN facilities would support the attainment of the Human Right to Sanitation for children aged five to 11 .

Humanitarian actors also have moral obligationsthe 'humanitarian imperative'-to take action 'to prevent or alleviate human suffering arising out of disaster or conflict' (Sphere Association 2018, p.28). This is enshrined in the Humanitarian Charter, which all agencies that endorse Sphere commit to (Sphere Association 2018). The provision of CHILD-SAN facilities acknowledges the right to live with dignity that the Humanitarian Charter advocates. 


\section{How the WASH sector can improve the provision of CHILD-SAN facilities}

Article 12 of the UN CRC states the right of children to be heard and to be taken seriously, and is one of the four general principles of the Convention, alongside the right to non-discrimination, the right to life and development, and the primary consideration of the child's best interests (UN 1990). Further, General Comment Number 12 states that this right 'does not cease in situations of crisis or in their aftermath' (Paragraph 125, United Nations Committee on the Rights of the Child 2009).

There is much literature on the value of child participation, summarised by the General Comment as 'helping children to regain control over their lives, contributing to rehabilitation, developing organisational skills and strengthening a sense of identity' with the caveat that 'care needs to be taken to protect children from exposure to situations that are likely to be traumatic or harmful' (Paragraph 125, United Nations Committee on the Rights of the Child 2009).

There is also much written on (a) the basic requirements of the implementation of a child's right to be heard, the foundational text being the Committee on the Rights of the Child's nine basic requirements of meaningful child participation (Paragraph 134, United Nations Committee on the Rights of the Child 2009), and (b) guidelines on how best to achieve child participation in humanitarian programming (notably O'Kane 2013a).

Yet despite many WASH sector-specific guidelines recommending the participation of children in the design of emergency sanitation facilities-most recently Oxfam's Sani Tweaks series (Oxfam 2018)and there being 'how to' materials available, few examples were found by either our systematic review of publications or Ferron and Lloyd's study on emergency WASH for children of all ages (Ferron and Lloyd 2014). This gives rise to the question: why are not children, including children with disabilities, being pro-actively involved and invited to participate in WASH programme design?

In 2017, the Humanitarian Innovation Fund (HIF) launched a WASH Innovation Challenge to pilot rapid community engagement for user-centred sanitation. In response, Eclipse Experience (Eclipse) and Save the Children developed a User-Centred Community Engagement (UCCE) methodology to improve the design of latrines and handwashing facilities for users including children aged 5 to 12 years (Eclipse Experience 2019). Oxfam's evaluation of the four projects implemented under the HIF challenge (two of which, in Bangladesh and Iraq, were implemented by Eclipse and Save the Children) found that time can be made to consult in a meaningful way even in short projects and that the use of welldesigned, tightly focused surveys with adequate representative sampling can find out much, quickly (Sandison 2017). Challenges for rapid, user-centred community engagement were also noted however, including that when there is restricted project scope at the project proposal and design stage, the possibilities of user-centred design are limited, and that the design of facilities only does not address users' further engagement in the implementation and maintenance of the infrastructure provided (Sandison 2017).

Oxfam concluded that the main potential of greater community engagement during an emergency response may be when projects move out of the acute response phases into the consolidation (or stabilisation) phase. It was therefore suggested that the initial infrastructure provided is used as a prototype on which the users can provide feedback, noting that this initial infrastructure should always incorporate the design fundamentals of access, dignity, privacy and safety, and be adaptable to ensure that it can become more sustainable (SuSanA 2012; Sandison 2017). O'Kane's (2013b) review of child participation in humanitarian programming similarly found that there are significant constraints to the safe and meaningful participation of children in the very early stages of an emergency response, and that there are more opportunities to strengthen children's participation in emergency preparedness and once the acute response phases have passed.

However, House (2019) found that the danger of relegating issues to 'when we have time' is that they will never be done and believes that even the simple consultation of a few people representing different groups can and should start right from the beginning of an emergency as this can lead to better initial prototypes that can then be improved through more involved participation and feedback.

CHILD-SAN therefore recommends (a) safe, meaningful and disability-inclusive child participation in emergency WASH preparedness planning, and (b) meaningful and disability-inclusive participation in emergency WASH programming from the earliest opportunity that it is safe to do so, using existing guidelines on how best to achieve child participation in humanitarian programming (notably O'Kane 2013a) (Table 3). For example, ensuring field staff have training and skills to communicate with children, including activities and budgets for children's participation in plans, and reporting against the global children's participation indicator (children's participation that is voluntary, safe and inclusive) (O'Kane 2013a). Such an approach will require commitment from 'senior to field levels (and) across agencies' (House 2019). The 
dissemination of the CHILD-SAN framework to WASH practitioners at all levels aims to raise the profile of the needs of children aged 5-11, which is not prominent in any existing guidance; and it is hoped will encourage an increase in awareness of the needs and commitment by providing an easy-to-use reminder of the key tenets of providing emergency sanitation for children aged five to 11 , with associated references when further detail is needed.

\section{Conclusion}

We have critically reviewed existing guidance for the provision of emergency sanitation for children aged five to 11 and subsequently presented a new disabilityinclusive framework (CHILD-SAN) that the WASH sector can use to better provide sanitation facilities for children. The framework recommends (a) safe and meaningful child participation in emergency WASH preparedness planning and emergency WASH programming as a means to develop contextually appropriate facilities, (b) specific design considerations for childfriendly toilets and (c) the collection of sex-, age- and disability-disaggregated data against contextually appropriate indicators to determine the prevalence of childfriendly facilities and their use.

We believe that the implementation of CHILD-SAN would contribute to the WASH sector's aims of achieving universal sanitation and maximising opportunities for good health, dignity, comfort and safety for all. Facilities that do not adhere to the recommendations of the CHILD-SAN framework are known to adversely impact the health, comfort and safety of children. Less is known about the impact on dignity, and our next steps will include research to understand the social and emotional impacts of social incontinence on children and their caregivers.

\footnotetext{
Abbreviations

ADCAP: Age and Disability Consortium; CCCs: Core Commitments for Children in Humanitarian Action; CFS: Child-friendly space; CRC: Convention on the Rights of the Child; GiHA: Gender in Humanitarian Action; HIF: Humanitarian Innovation Fund; HRP: Humanitarian Response Plan; HRWS: Human Rights to Water and Sanitation; IAD: Incontinence-associated dermatitis; IDP: Internally displaced people; OCHA: United Nations Office for the Coordination of Humanitarian Affairs; QAAP: Quality Assurance and Accountability Project; SADD: Sex-and Age-Disaggregated Data; SDGs: Sustainable Development Goals; UCCE: User-Centred Community Engagement; UN: United Nations; UNICEF: United Nations Children's Fund; UNHCR: United Nations High Commissioner for Refugees; WASH: Water, Sanitation and Hygiene; WHO: World Health Organization.
}

\section{Supplementary Information}

The online version contains supplementary material available at https://doi. org/10.1186/s41018-021-00107-6.

Additional file 1: Table 1. Classification of publications as meeting Criterion $2 \mathrm{a}$ and/or Criterion $2 \mathrm{~b}$.

\section{Acknowledgements}

We acknowledge and thank Suzanne Ferron and Sarah House, whose suggestions improved the paper considerably.

\section{Authors' contributions}

CRS initiated the report; conducted the systematic review and analysis; wrote the first draft of the manuscript; and updated the manuscript for review comments. DJB provided guidance on the overall study. DJB and BEE provided review comments; and read and approved the final manuscript. The author(s) read and approved the final manuscript.

\section{Funding}

CRS is a PhD Candidate at the University of Leeds (United Kingdom) funded by the Engineering and Physical Sciences Research Council (EPSRC)

\section{Availability of data and materials}

Not applicable.

\section{Declarations}

\section{Competing interests}

The authors declare that they have no competing interests.

\section{Author details}

${ }^{1}$ School of Civil Engineering, University of Leeds, Leeds, West Yorkshire LS2 9JT, UK. ${ }^{2}$ School of Population and Global Health, The University of Western Australia, 35 Stirling Highway, Crawley, Western Australia 6009, Australia.

Received: 24 September 2019 Accepted: 8 September 2021

Published online: 06 October 2021

\section{References}

Age and Disability Consortium (2018) Humanitarian inclusion standards for older people and people with disabilities. https://reliefweb.int/report/ world/humanitarian-inclusion-standards-older-people-and-people-disab ilities. Accessed 14 Nov 2018

Banzet J (2003) Towards child-friendly latrines in Viet Nam. Waterfront 16:18-19.

Bastable A, Lamb J (2012) Innovative designs and approaches in sanitation when responding to challenging and complex humanitarian contexts in urban areas. Waterlines 31. https://doi.org/10.3362/1756-3488.2012.007

Behnke N, Cronk R, Snel M et al (2018) Improving environmental conditions for involuntarily displaced populations: water, sanitation, and hygiene in orphanages, prisons, and refugee and IDP settlements. J Water Sanit Hyg Dev:1-7. https://doi.org/10.2166/washdev.2018.019

Brown J (2019) Oxfam views \& voices: three things we've learned about measuring quality in humanitarian WASH responses. https://views-voices. oxfam.org.uk/2019/07/measuring-quality-wash-responses/. Accessed 8 Aug 2019

Deniel K (2006) Children's sanitation in emergencies. Waterlines 24:28. https:// doi.org/10.3362/0262-8104.2006.012

Denis J (2015) Sanitation practices for infants and children in emergencies. Dissertation, Cranfield University, Cranfield

Eclipse Experience (2019) User-centred community engagement. http:// www.eclipse-experience.com/user-centred-community-engagement. Accessed 8 Mar 2019 
Farrington M (2018) Women's Social Architecture Project: phase 1 final report Cox's Bazaar https://oxfam.app.box.com/s/gmiigfdn7ntbxeve7fikllywf itnkcjy/file/384891125807. Accessed 11 Dec 2018

Farrington M (2019) Conversation with Claire Rosato-Scott 20 February 2019

Ferron S, Lloyd A (2014) Emergency WASH for children. https://www.elrha.org/ wp-content/uploads/2015/02/2014-10-11-Emergency-WASH-for-Child ren-Final.pdf. Accessed 1 Nov 2018

Gensch R, Jennings A, Renggli S, Reymond P (2018) Compendium of sanitation technologies in emergencies. https://www.eawag.ch/fileadmin/ Domain1/Abteilungen/sandec/schwerpunkte/sesp/Emergencies/compe ndium_emergencies.pdf. Accessed 22 Feb 2019

Global WASH Cluster (2019) Global WASH cluster annual meeting report. Global WASH Cluster, Geneva

Groupe URD (2019) Analysis of the capacity of the WASH sector. https:// www.urd.org/en/publication/analysis-of-the-capacity-of-the-washsector-june-2019/. Accessed 1 Aug 2019

Hafskjold B, Pop-Stefanija B, Giles-Hansen C et al (2016) Taking stock: incompetent at incontinence - why are we ignoring the needs of incontinence sufferers? Waterlines 35. https://doi.org/10.3362/17563488.2016 .018

Harvey P (2007) Excreta disposal in emergencies. https://wedc.ac.uk/publi cations/. Accessed 7 Mar 2019

House S (2019) Strengthening the humanity in humanitarian action in the work of the WASH sector in the Rohingya response. https://www. humanitarianlibrary.org/resource/strengthening-humanity-humanitari an-action-work-wash-sector-rohingya-response-gender-gbv. Accessed 25 Mar 2019

Jabbar GA (2018) Gender-based violence in relation to water, sanitation and hygiene in the informal tented settlements of the Bekaa Valley, Lebanon. Dissertation, University of Leeds, Leeds

Jones H, Wilbur J (2014) Compendium of accessible WASH technologies. https://washmatters.wateraid.org/publications/compendium-of-acces sible-wash-technologies. Accessed 17 May 2017

Langford M, Bartram J, Roaf V (2017) The human right to sanitation. In: Langford M, Russell AFS (eds) The human right to water: theory, practice and prospects. Cambridge University Press, Cambridge, pp 345-395

Mazurana D, Benelli P, Walker P (2013) How sex-and age-disaggregated data and gender and generational analyses can improve humanitarian response. Disasters 37:S68-S82. https://doi.org/10.1111/disa.12013

Moher D, Liberati A, Tetzlaff J et al (2009) Preferred reporting items for systematic reviews and meta-analyses: the PRISMA statement. PLoS Med 6:e1000097. https://doi.org/10.1371/journal.pmed.1000097

Noortgate JVD, Maes P (2010) Public Health Engineering in precarious situations. http://refbooks.msf.org/msf_docs/en/public_health/public_ health_en.pdf. Accessed 18 Nov 2018

O'Kane C (2013a) Guidelines for children's participation in humanitarian programming. https://reliefweb.int/sites/reliefweb.int/files/resources/ Children_Participation_Humanitarian_Guidelines.pdf. Accessed 31 Mar 2019

O'Kane C (2013b) Review of children's participation in humanitarian programming. https://www.alnap.org/system/files/content/resource/ files/main/children-participation-humanitarian-review.pdf. Accessed 18 Nov 2018

OCHA (2018) Global humanitarian overview 2019. https://www.unocha.org/ global-humanitarian-overview-2019. Accessed 10 Jan 2019

OCHA (2019) Humanitarian response plan. https://www.humanitarianres ponse.info/en/operations/nigeria/humanitarian-response-plan. Accessed 18 July 2019

OCHA (2020) Global humanitarian overview 2021. https://www.unocha.org/ global-humanitarian-overview-2021. Accessed 8 Feb 2021

Oxfam (2013) Oxfam Minimum Requirements for WASH Programmes (MRWASH). https://policy-practice.oxfam.org.uk/publications/oxfam-minim um-requirements-for-wash-programmes-mr-wash-300134. Accessed 18 Nov 2018

Oxfam (2018) Sani Tweaks. Best practices in sanitation. www.oxfam.org.uk/ sanitweaks. Accessed 31 Mar 2019

Rosato-Scott CA, Giles-Hansen C, House S, et al (2019) Guidance on supporting people with incontinence in humanitarian and low- and middle-income contexts (LMICs). https://wash.leeds.ac.uk/wp-conte nt/uploads/sites/45/2019/08/Guidance-document_August-2019_Versi on_1.pdf. Accessed 16 Aug 2019
Ryan F (2018) 'It's horrifically painful': the disabled women forced into unnecessary surgery. https://www.theguardian.com/society/2018/ aug/06/disabled-women-surgery-catheter-accessible-toilets. Accessed 27 Feb 2019

Sandison P (2017) We're listening: an evaluation of user-centred community engagement in emergency sanitation. https://oxfamilibrary.openr epository.com/bitstream/handle/10546/620617/gd-listening-commu nity-engagement-emergency-sanitation-050219-en.pdf?sequence = 1 \& isAllowed=y. Accessed 15 Feb 2019

Save the Children (2013) WASH for children in emergencies. https://www. elrha.org/wp-content/uploads/2015/02/Annex-E-Hygiene_Promo tion_September_Newsletter_2013.pdf. Accessed 10 Jan 2019

Sommer M, Schmitt M, Clatworthy D (2017) A toolkit for integrating Menstrual Hygiene Management (MHM) into humanitarian response. https://www.humanitarianlibrary.org/resource/toolkit-integratingmenstrual-hygiene-management-mhm-humanitarian-response. Accessed 26 Feb 2021

Sphere Association (2018) The sphere handbook: humanitarian charter and minimum standards. www.practicalactionpublishing.org/sphere. Accessed 14 Nov 2018

SuSanA (2012) Sustainable sanitation for emergencies and reconstruction situations. www.humanitarianreform.org. Accessed 6 Mar 2019

Tanner S, O'Connor M (2017) A safe place to shine. Creating opportunities and raising voices of adolescent girls in humanitarian settings. https:// www.rescue.org/sites/default/files/document/2248/irccompassgloba Ireport.pdf. Accessed 14 Mar 2019

The Alliance for Child Protection in Humanitarian Action (2019) Table of indicators: minimum standards for child protection in humanitarian action, 2019 edition. https://alliancecpha.org/en/CPMS_Table_Indic ators. Accessed 10 Feb 2020

UNHCR (2018a) UNHCR WASH manual. Practical guidance for refugee settings. http://wash.unhcr.org/unhcr-wash-manual-for-refugee-settings/. Accessed 14 Nov 2018

UNHCR (2018b) UNHCR Core WASH indicators. https://wash.unhcr.org/ unhcr-wash-standards-and-indicators-for-refugee-settings/. Accessed $25 \mathrm{Jan} 2019$

UNHCR (2020) UNHCR population statistics. https://www.unhcr.org/refug ee-statistics/download/?url=E1ZxP4. Accessed 8 Feb 2021

UNICEF (2010) Core commitments for children in humanitarian action. www.unicef.org. Accessed 30 Nov 2018

UNICEF (2012) Water, sanitation and hygiene (WASH) in schools. UNICEF, New York

UNICEF (2017a) Guidance: including children with disabilities in humanitarian action - WASH. https://training.unicef.org/disability/emergencies/ downloads/UNICEF_WASH_English.pdf. Accessed 22 Feb 2019

UNICEF (2017b) UNICEF target product profile: accessible latrine slab for emergencies. https://www.unicef.org/supply/files/2017.04.05_Acces sible_Latrine_Slab_TPP_v2.2.pdf. Accessed 21 Feb 2019

UNICEF (2018) Humanitarian Action for Children 2018. https://www.unicef. org/eca/reports/unicefhumanitarian-action-children-2018. Accessed 14 Mar 2019

United Nations (1990) The United Nations convention on the rights of the child. https://www.unicef.org.uk/what-we-do/un-convention-child-rights/. Accessed 7 Nov 2018

United Nations (2010a) UNGA Resolution 64/292. The human right to water and sanitation. https://undocs.org/en/A/RES/64/292. Accessed 17 Mar 2019

United Nations (2010b) HRC Res 15/9. Human rights and access to safe drinking water and sanitation. https://undocs.org/A/HRC/RES/15/9. Accessed 17 Mar 2019

United Nations (2015) UNGA Resolution 70/169. The human rights to safe drinking water and sanitation. https://undocs.org/en/A/RES/70/169. Accessed 17 Mar 2019

United Nations (2016) Sustainable development goal 6. https://sustainabl edevelopment.un.org/sdg6. Accessed 15 Nov 2018

United Nations Committee on the Rights of the Child (2009) General comment on A12 Right to Be Heard. http://www.crae.org.uk/publicationsresources/uncrc-general-comment-on-right-to-be-heard-(article-12)/. Accessed 31 Mar 2019

Veneme V (2015) The unlikely sanitary pad missionary. https://www.bbc.co. uk/news/magazine-34925238. Accessed 8 May 2019 
Visser M (2012) External evaluation WASH provision in Bahn refugee camp in Nimba, Liberia. https://www.alnap.org/system/files/content/resou rce/files/main/acf-bahn-camp-liberia-wash-evaluation-report.pdf. Accessed 7 Mar 2019

WHO (2006) Constitution of the World Health Organisation. WHO, Geneva. Accessed 31 Jan 2019

WHO (2008) Managing WHO humanitarian response in the field. https:// www.who.int/hac/techguidance/tools/full_manual.pdf. Accessed 14 Nov 2018

WHO (2018) Health topics: sanitation. https://www.who.int/topics/sanit ation/en/. Accessed 17 Mar 2019

Yates T, Allen Vujcic J, Leandre Joseph M et al (2018) Efficacy and effectiveness of water, sanitation, and hygiene interventions in emergencies in low-and middle-income countries: a systematic review. Waterlines 37. https://doi.org/10.3362/1756-3488.17-00016
Zhou F, Xue K, Liu Y et al (2019) Toileting behaviors and factors associated with urinary incontinence in college-aged female students in China. Int Urogynecol J. https://doi.org/10.1007/s00192-019-04043-3

Zomerplaag J, Moojiman A (2005) Child-friendly hygiene and sanitation facilities in schools: indispensable to effective hygiene education. https://www.ircwash.org/sites/default/files/Zomerplaag-2005-Child.pdf. Accessed 10 Mar 2019

\section{Publisher's Note}

Springer Nature remains neutral with regard to jurisdictional claims in published maps and institutional affiliations.

\section{Submit your manuscript to a SpringerOpen ${ }^{\circ}$ journal and benefit from:}

- Convenient online submission

- Rigorous peer review

- Open access: articles freely available online

- High visibility within the field

- Retaining the copyright to your article

Submit your next manuscript at springeropen.com 